\title{
A simple qualitative approach for mapping regional landslide susceptibility in the Faroe Islands
}

\author{
M.-P. J. Dahl ${ }^{1,2}$, L. E. Mortensen ${ }^{2}$, A. Veihe ${ }^{1}$, and N. H. Jensen ${ }^{1}$ \\ ${ }^{1}$ Department of Environmental, Social and Spatial Change, Roskilde University, Universitetsvej 1, P.O. Box 260, \\ 4000 Roskilde, Denmark \\ ${ }^{2}$ Jarðfeingi (Faroese Earth and Energy Directorate), Brekkutun 1, 0110 Tórshavn, Faroe Islands
}

Received: 9 June 2009 - Revised: 6 January 2010 - Accepted: 17 January 2010 - Published: 1 February 2010

\begin{abstract}
The Faroe Islands in the North Atlantic Ocean are highly susceptible to landslides. Following recent landslide incidents, Jarðfeingi (Faroese Earth and Energy Directorate) has pointed out, that the risk of human lives or of property being lost or affected by landslides may be increasing. This paper aims at presenting and testing a simple qualitative approach for mapping regional landslide susceptibility in the Faroe Islands, using few key parameters. The susceptibility model holds information about both landslide initiation areas and runout zones. Landslide initiation areas are determined from slope angle thresholds $\left(25^{\circ}-40^{\circ}\right)$ and soil cover data, while runout zones are delineated using the angle of reach approach taking into account the presence/absence of geological benches in the runout path, which has not been considered in earlier studies. Data input is obtained from a landslide database containing 67 debris flows throughout the Faroe Islands. Angle of reach values differ significantly with the presence/absence of geological benches in the runout path. Two values of angle of reach, $21.5^{\circ}$ and $27.6^{\circ}$, are used for calculating runout zones. The landslide susceptibility model is tested in a study area at the town of Klaksvík in the northern part of the Faroe Islands. A map validation comparing predicted susceptibility zones with a validation-dataset of 87 actual landslides in the study area reveal that $69 \%$ and $92 \%$, respectively, of actual landslide initiation areas and runout zones are correctly predicted. Moreover $87 \%$ of the actual landslides are included in the overall predicted landslide susceptibility areas.
\end{abstract}

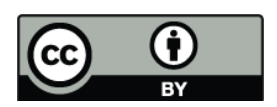

Correspondence to: M.-P. J. Dahl (mpjd@ruc.dk)

\section{Introduction}

The Faroe Islands in the North Atlantic Ocean (Fig. 1) are highly susceptible to landslides. The 18 islands, covering an area of $1397 \mathrm{~km}^{2}$, are dominated by high mountains rising from the ocean to a height of app. $900 \mathrm{~m}$ above sea level ( $\mathrm{m}$ a.s.l.). Landslides are mainly rock falls and debris flows as defined by Cruden and Varnes (1996). Particularly the latter are very common (Dahl, 2007), due to steep landscape, high precipitation (900-3200 mm/yr), (Cappelen and Laursen, 1998), and basaltic parent material overlain by a colluvial soil layer ranging from 0 to $8 \mathrm{~m}$ (Dahl, 2007). During recent years damaging landslide events, mainly triggered by extreme rainfalls, have led to increased focus on loss of human lives and property caused by debris flows. Jarðfeingi (Faroese Earth and Energy Directorate) has pointed out, that landslide risk to the population and to human activities may be increasing due to climate change and to the fact that human activities are taking up still larger areas of the Faroese landscape (Mortensen, 2001, 2004). There is hence a growing need for developing landslide susceptibility maps which may be used for planning purposes.

Landslide susceptibility is generally seen as expressing the likelihood that a landslide will occur in an area as a function of local terrain conditions (Soeters and Van Westen, 1996). In other words, a landslide susceptibility map points out areas, which are likely to hold landslides in the future (Brabb, 1984). Several authors have emphasized, that mapping landslide susceptibility should include both recognition of landslide initiation areas and an assessment of runout behavior of the landslide material (Dai et al., 2002; Corominas et al., 2003; Hürlimann et al., 2006; Guinau et al., 2007).

The available methods to map landslide initiation susceptibility can be divided into qualitative and quantitative approaches. Qualitative approaches include landslide inventory

Published by Copernicus Publications on behalf of the European Geosciences Union. 
mapping or expert evaluation (Malgot and Mahr, 1979; Ives and Messerli, 1981; Rupke et al., 1988; Wachal and Hudak, 2000; Morton et al., 2003; Sarkar and Anbalagan, 2008), while quantitative approaches can be divided into mechanistic (Terlien et al., 1995; Wu and Sidle, 1995; Alcantara-Ayala, 2004; Collins and Znidarcic, 2004; Dahl, 2007) and statistical methods (Ayalew and Yamagishi, 2005; Domínguez-Cuesta et al., 2007; Guinau et al., 2007; Magliulo et al., 2008). Mapping landslide initiation susceptibility by the use of expert evaluation is the qualitative approach most broadly used (He and Beighley, 2008), and is also the method chosen for this paper. Expert evaluation allows landslide prone areas to be determined through fieldwork and subsequent analysis, taking into account a variety of geological, hydrological, geomorphologic and land use parameters (Rupke et al., 1988; Huabin et al., 2005; Sarkar and Anbalagan, 2008). Although the subjectivity involved in weighing and rating the parameters as well as the reproducibility of the results constitute disadvantages to the approach (Dai and Lee, 2002; Dai et al., 2002; Huabin et al., 2005), mapping landslide initiation areas by the use of expert evaluation in many cases can be done successfully at any scale (He and Beighley, 2008).

When mapping runout distances of landslides, empirical (Cannon and Savage, 1988; Corominas, 1996; Dai and Lee, 2002; Corominas et al., 2003), analytical (Hutchinson, 1986; Sassa, 1988) or numerical approaches (McDougall and Hungr, 2004; De Blasio et al., 2005; Valentino et al., 2008; Wang et al., 2008) can be used. A simple empirical method which is used in many papers, although it cannot delineate a travel path (Dai et al., 2002), is the angle of reach (AOR) approach. The AOR, which was first introduced by Heim (1932) as the Fahrböschung, is defined as the angle connecting the crown of a landslide with the distal margin of the runout material. Since introduced by Heim, correlations between AOR and changes in landslide volume, type and runout path have been investigated by many authors (e.g. Scheidegger, 1973; Hsü, 1975; Corominas, 1996; Dai and Lee, 2002; Corominas et al., 2003). However, an aspect of the approach not yet examined is the change in AOR as a consequence of a stepwise landscape seen as geological benches in the runout path. In this paper, different AOR values were calculated taking into account the presence/absence of geological benches in the runout path and implemented in the landslide susceptibility model.

Previous works on landslides in the Faroe Islands are very sparse. Jørgensen (1978) described the morphology of 9 mainly rock slides, originating from late or post glacial time, in Suðuroy (the southernmost island of the Faroe Islands), three of which have later been redefined as rock glaciers (Humlum, 1998). In a multidisciplinary study by Lawson et al. (2005) it was found that from 2000-4000 yr BP, a general slope destabilization in the Faroe Islands occurred, most likely due to climate changes. When analyzing 4 soil pits on a slope at Klaksvík on the island Borðoy Christiansen et al. (2007) identified app. 10 organic-rich layers which had been buried by debris flow runout material. Of the 10 layers, 7 were dated to between 7940-2060 yr BP (Christiansen et al., 2007). Dahl (2007) conducted a mechanistic landslide susceptibility assessment on a 1:1000 scale using the infinite slope model (Ward, 1976; Selby, 1993). The result was highly affected by the large local variations of soil depth and cohesion (Dahl, 2007). Large variations in Faroese soil properties are also found in Hansen (1990), and Veihe and Thers (2007). The large local variation in soil parameters is a major obstacle for potentially assessing regional landslide susceptibility in the Faroe Islands using a mechanistic approach.

The purpose of this paper was to test a simple qualitative approach for mapping regional landslide susceptibility in the Faroe Islands, using only few key parameters. The susceptibility model contained information about both landslide initiation areas, which were determined from slope angle thresholds and soil cover data, and runout zones, which were delineated using the AOR approach. A novel approach taking into account the presence/absence of geological benches in the runout path, were used for calculating AOR values. The model was tested in a study area at the town of Klaksvík in the northern part of the Faroe Islands by producing a GISbased landslide susceptibility map. A simple approach for assessing susceptibility was chosen because of its advantage of being easy and fairly inexpensive to carry out and to extrapolate to other landslide prone areas in the Faroe Islands, as discussed in Sect. 6.

\section{Landslide characteristics}

Landslides in the Faroe Islands are mainly rock falls and rainfall-triggered debris flows as defined by Cruden and Varnes (1996). Particularly debris flows are very common and are the only landslides considered in this paper. Hence only these landslides are described in detail in the following section. Most debris flows are open-sloped, while few are channelized. Landslide initiation is shallow and translational with slide planes either occurring within the soil, at the contact zone between the soil and the underlying rocky parent material, or in combination between the two. Slide planes never occur within the rocky parent material. In most of the landslides, runout material reaches valley bottoms, but do not travel further down the valley. In general, erosion and entrainment along the runout path is negligible.

\section{Study area}

The study area has an extension of $8.15 \mathrm{~km}^{2}$ and is located at the town of Klaksvík $(62.13 \mathrm{~N} ; 6.34 \mathrm{~W})$ on the island Borðoy in the northern part of the Faroe Islands (Fig. 1). The town has app. 4700 inhabitants, making it the second largest town of the islands. 


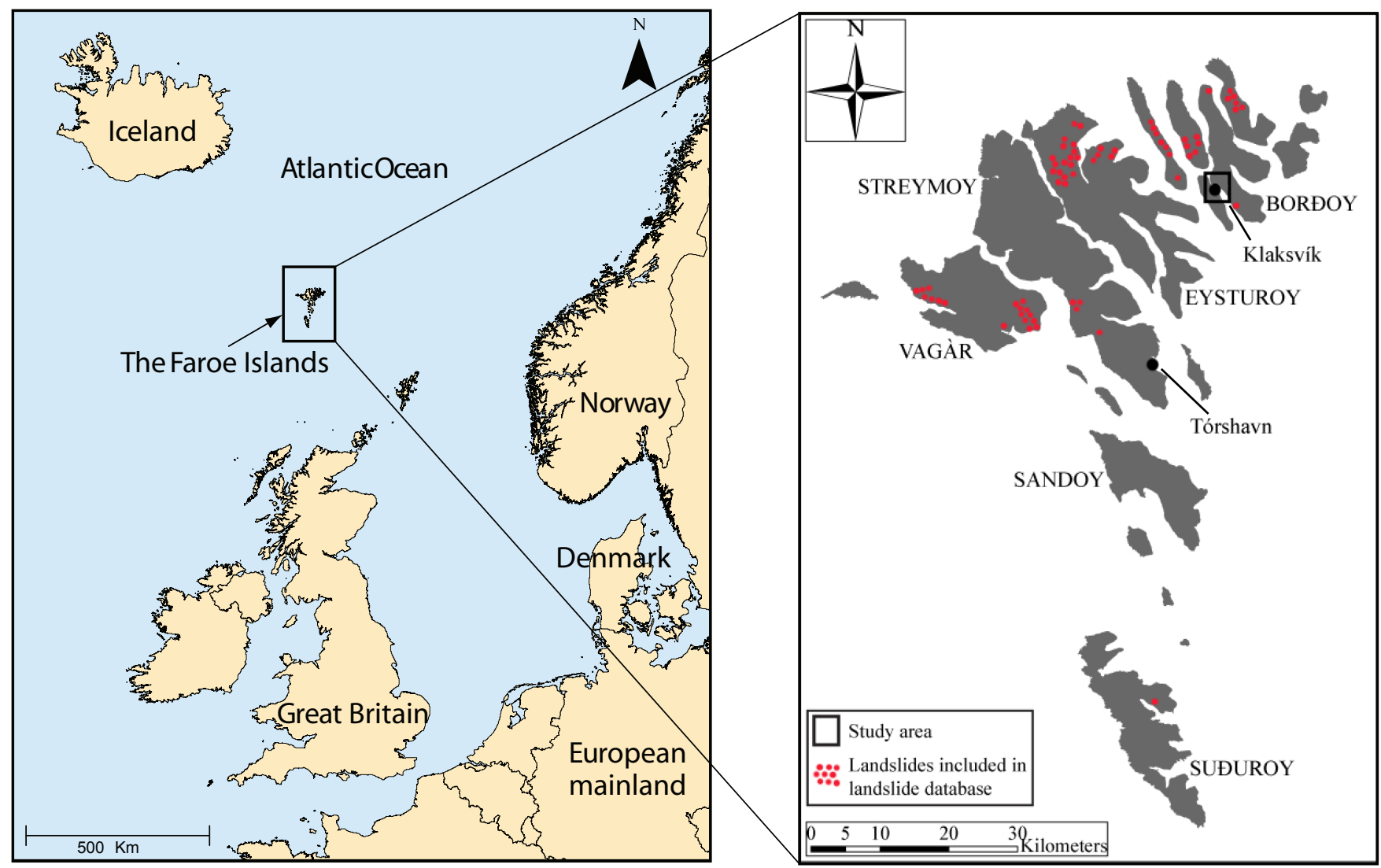

Fig. 1. Location of the Faroe Islands, the study area and landslides included in the landslide database.

Klaksvík is located at sea level surrounded by fjords and steep mountain sides, which rise to app. $650 \mathrm{~m}$ a.s.l. As in many other towns and villages of the Faroe Islands, new buildings and infrastructure can be established mainly uphill on the steep slopes, thus increasing the landslide threat to the population and to human activities. A large number of landslide scars and runout deposits on the mountain sides surrounding Klaksvík and several historic events indicate that these slopes are highly susceptible to landslides and snow avalanches. In 1745 and in 1765 large snow avalanches struck the town, the latter killing 19 people (Christiansen et al., 2007). Moreover, in 2000 following heavy rain (200$300 \mathrm{~mm} / 48 \mathrm{~h}$ ), a debris flow struck a house and a construction area in the town (Christiansen et al., 2007).

The climate in the Faroe Islands at sea level is temperate oceanic, humid and windy with mild winters and cool summers. Annual precipitation in the study area is $2710 \mathrm{~mm}$, measured at the nearest climate station app. $3 \mathrm{~km}$ north of Klaksvík at $6 \mathrm{~m}$ a.s.l. (Cappelen and Laursen, 1998). The mean annual air temperature (MAAT) a.s.l. for the Faroe Islands is $6.5^{\circ} \mathrm{C}$ (Cappelen and Laursen, 1998). However, a mean annual lapse rate of $-0.0077^{\circ} \mathrm{C} / \mathrm{m}$ (Christiansen and Mortensen, 2002), results in a MAAT about $1.5^{\circ} \mathrm{C}$ at the highest points within the study area.
The Faroe Islands are remnants of an ancient basalt plateau originating from volcanic activity related to the tertiary opening of the NE Atlantic Ocean (Rasmussen and Noe-Nygaard, 1969a). The plateau mainly consists of three tholeiitic basalt formations which are built up of numerous lava flows (Rasmussen and Noe-Nygaard, 1969a). In the study area, the parent material consists of the middle basalt formation (Malinstindur Formation), and the upper basalt formation (Enni Formation), respectively (Rasmussen and Noe-Nygaard, 1969b; Passey and Bell, 2007). The upper part of the Malinstindur Formation which make up the parent material from sea level to app. $120 \mathrm{~m}$ a.s.l. in the study area (Rasmussen and NoeNygaard, 1969b), consists of plagioclase-phyric lava flows with a thickness from $<1$ to app. $10 \mathrm{~m}$ (Rasmussen and NoeNygaard, 1969a). The Enni formation, making up the parent material in the rest of the study area mainly consists of aphyric, crypto-phyric and olivine-phyric lava flows with a thickness from app. 8 to $11 \mathrm{~m}$ (Rasmussen and Noe-Nygaard, 1969a). The two basalt formations in the study area are dipping app. $1.4^{\circ}$ towards SE, and interbasaltic tuff-layers with a thickness of $>1$ to app. $4 \mathrm{~m}$ are mainly found between the lava flows in the Enni Formation (Rasmussen and NoeNygaard, 1969a). 
Water and wind erosion, together with chemical and physical weathering and the quaternary glacial erosion has broken down the original basalt plateau and created the present glaciated Faroese landscape (Humlum, 1996; Christiansen, 1998). The lower parts of the study area are dominated by a concave landscape, cirque valleys and streams in between free face geological benches, which are remnants of the ancient lava flows. The geological benches (henceforward referred to as basalt benches) and steeper slopes become more dominant with altitude a.s.l. until reaching the top of the ancient basalt plateau, which is seen as essentially flat mountain tops and upper convexities. Present soil formation began after the Weichselian ice age, and soil depths in the study area vary from 0 to app. $3.5 \mathrm{~m}$. Soil formation in the study area and in the Faroe Islands in general is highly dominated by sedimentological processes (Dahl, 2007; Veihe and Thers, 2007). This is exemplified by organic-rich soil layers buried by landslide runout material (Christiansen et al., 2007; Dahl, 2007) as well as a high gravel and stone content in the soil (Rutherford and Debenham, 1981; Veihe and Thers, 2007; Dahl, 2007) originating from downslope landslide and water transport processes. Thus the soil can be characterized as colluvial. Analysis from three soil pits in the study area define soil texture as sandy loam and loamy sand according to the USDA (1975) soil texture classification system (Dahl, unpublished), which is in good agreement with results from Dahl (2007) and Veihe and Thers (2007). Grasses and herbs, which is the only vegetation covering the area, is grazed by sheep throughout the year.

\section{Methodology}

The landslide susceptibility zonation was prepared considering slope angle thresholds, soil cover data (presence/absence of soil on the underlying parent material) and runout zones, determined using the AOR approach. Input data were collected from a database containing 67 landslides visited and examined throughout the Faroe Islands. Subsequently, landslide initiation areas, based on observed critical slope angles for landslide initiation, and runout zones were delineated within the study area by the use of GIS (ESRI ArcMap 9.3), creating a landslide susceptibility map. The susceptibility model was validated by comparing it with a validationdataset showing the spatial occurrence of actual landslides in the study area. Thereby two different landslide datasets and geographical areas were used for constructing and validating the landslide susceptibility model.

\subsection{Landslide database}

To define the susceptibility zonation and to describe the landslide characteristics, a database was prepared with the information collected from 67 debris flows throughout the Faroe Islands. Landslides included in the database were selected using two criteria: 1) They should have a surface of rupture length $>10 \mathrm{~m}$ to be considered large enough to cause damage to human activities, had they occurred near infrastructure or populated areas. 2) If possible they should be placed in close vicinity to each other, making it possible to visit a large number of landslides in a limited period of time. There were no preferences regarding slope angle, altitude, geology, land use, vegetation, soil depth or slope aspect.

For each of the 67 landslides (Fig. 1) surface of rupture depth, slide plane, slope angle and AOR were determined in the field. The surface of rupture depth was measured according to the definitions of landslide dimensions in Cruden and Varnes (1996). The slide plane was designated either to be within the soil, at the contact zone between soil and underlying rock, or a combination between the two. The slope angle and the AOR were measured using a hand held inclinometer. The two angles were measured from the bottom of the landslide scar and from the distal margin of the runout zone to the crown of the scar, respectively (Fig. 2).

\subsection{The susceptibility model and map}

Exploiting digital orthophotos (resolution: $0.5 \mathrm{~m}$ ) georeferenced with a digital elevation model (DEM) in a TIN environment in GIS (ESRI ArcMap 9.3) (the DEM was derived from a 1:20000 scale topographic map; equidistance: $10 \mathrm{~m}$ ), it was possible to measure surface of rupture width, horizontal surface of rupture length and horizontal landslide length (Lh) (Fig. 2). The two latter, together with observed values of slope angle and AOR, were utilized to compute landslide height $(H)$, surface of rupture length and landslide length (L) (Cruden and Varnes, 1996). Landslide volumes were estimated using Eq. (1) (Cruden and Varnes, 1996).

Landslide volume $=\frac{1}{6} \pi D_{\mathrm{r}} W_{\mathrm{r}} L_{\mathrm{r}}$

where $D_{\mathrm{r}}$ is the surface of rupture depth, $W_{\mathrm{r}}$ is the surface of rupture width and $L_{\mathrm{r}}$ is the surface of rupture length. Lower and higher slope angle thresholds for landslide initiation and an overall average AOR were determined. Furthermore, potential correlations between AOR and landslide volume as well as occurrence of basalt benches in the runout path were investigated. This was done because several studies have shown correlations between AOR and either landslide volume or obstructions in the runout path (Scheidegger, 1973; Hsü, 1975; Corominas, 1996; Dai and Lee, 2002; Corominas et al., 2003). The purpose of calculating average AOR values was to use these to delineate runout zones in the final susceptibility map. A correlation which was found between AOR and the occurrence of basalt benches in the runout path led to calculation of two different average AOR values depending on whether or not any basalt benches were present in the 


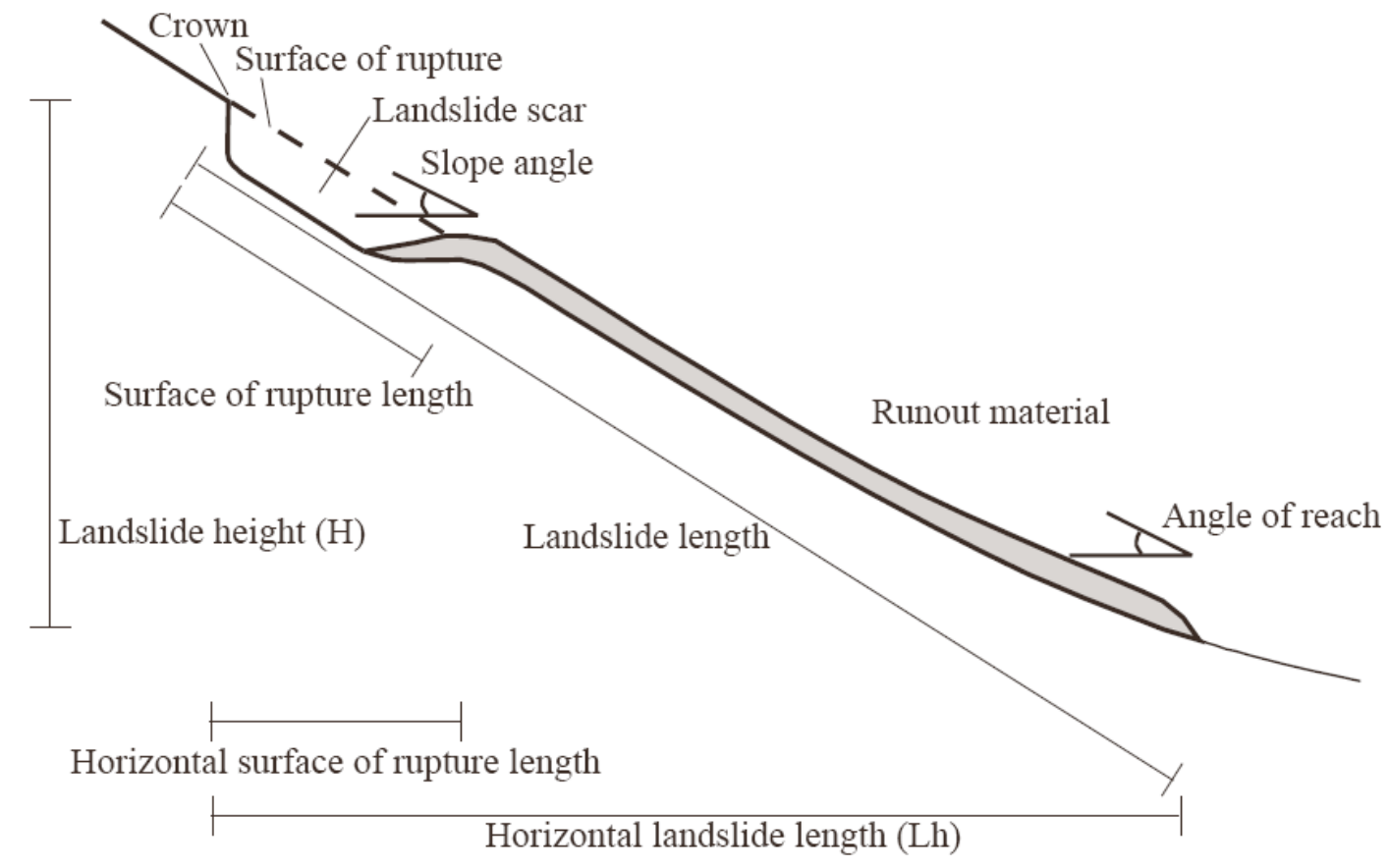

Fig. 2. Landslide dimension terminology used in this paper.

runout path. All AOR values were calculated through linear regression (cf. Sect. 5.2) and simple trigonometry, Eq. (2).

$\mathrm{AOR}=\tan ^{-1}\left(\frac{H}{L h}\right)$

A maximum horizontal landslide length $(L h)$ of $374 \mathrm{~m}$, was used to calculate AOR values, since this was the maximum horizontal landslide distance measured in the landslide database and in the Faroe Islands.

Areas having slope angles between $25^{\circ}$ and $40^{\circ}$, which from data in the landslide database had been recognized as being susceptible to landslide initiation (cf. Sect. 5.1) were delineated within the study area using the DEM. Areas not covered with soil were identified on the orthophotos and excluded from the landslide initiation susceptibility zones as well as susceptibility zones less than $10 \mathrm{~m}$ in length.

Runout zones were calculated from average AOR values by substituting $L h$ with $374 \mathrm{~m}$ in equations of Table 3 . At the highest hillslope point and $10 \mathrm{~m}$ above the bottom of each defined landslide initiation area as well as for every $100 \mathrm{~m}$ along the mountain side a landscape profile down the slope, parallel to the slope angle orientation, was drawn in GIS. At each profile, it was visually estimated from the digital orthophotos and from the shape of the drawn profile, whether or not any basalt benches were present in the runout path. Figure 3 shows examples of landscape profiles with and without basalt benches.

Dependent on whether basalt benches were estimated to be present or absent in each runout path, $\mathrm{X}$ and $\mathrm{Y}$ coordinates for a straight AOR-line starting in the same point as the drawn landscape profile, and declining with AOR were calculated and visualized together with the drawn landscape profile in GIS. At landscape profiles without basalt benches an average AOR value of $21.5^{\circ}$ was used (cf. Sect. 5.2), and the runout length was defined to the point where the AORline intersected the landscape profile (Fig. 3a). At landscape profiles with basalt benches an average AOR value of $27.6^{\circ}$ was used (cf. Sect. 5.2), and the runout length was defined to the farthest point where the AOR-line intersected the landscape profile (Fig. 3b), since runout material was observed to be able to overrun basalt benches in the landscape.

At all landscape profiles, estimated runout lengths were visualized as downslope endpoints in GIS and connected to delineate final runout zones.

\subsection{Validation}

The landslide susceptibility model was evaluated by comparing predicted landslide initiation areas and runout zones with a validation-dataset showing the spatial occurrence of 87 landslides observed in the study area. Each landslide was localized from digital orthophotos, and split up into an initiation area and a runout zone. After pointing out the actual landslides in GIS, the percentage of observed initiation areas and runout zones present in the predicted landslide initiation areas and runout zones, as well as in predicted nonsusceptible areas was calculated. Furthermore, actual landslides included in the overall predicted landslide susceptibility areas were counted. 

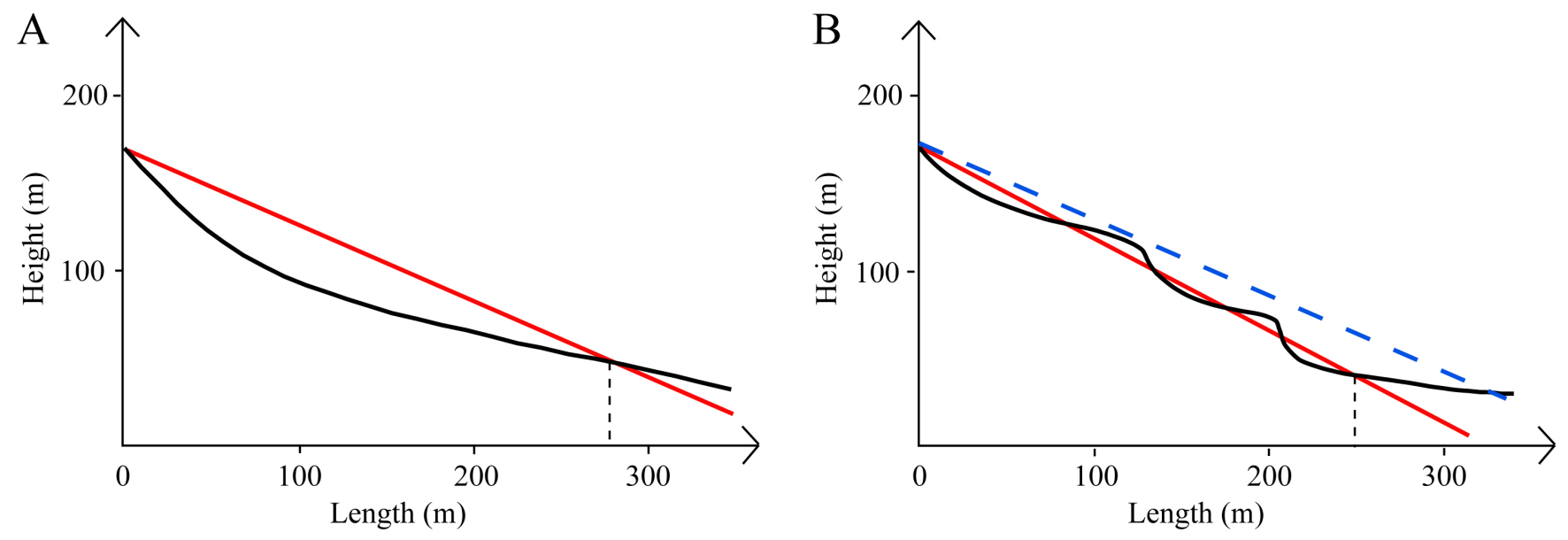

Fig. 3. Graphs showing landscape profiles (black lines), AOR-lines used in the susceptibility model (red lines) and AOR-line representing "true" dynamic friction coefficient when basalt benches are present in the runout path (blue dashed line). Black dashed lines are showing runout lengths. (A) Landscape profile without basalt benches, (B) Landscape profile with basalt benches.

\subsection{Statistical analysis}

Variations in landslide parameters from the landslide database were described using coefficients of variation (CV). Potential correlations between landslide volume and AOR were tested by use of Spearman Rank Correlation Coefficient. Linear regression between horizontal landslide length $(L h)$ and landslide height $(H)$ was described using the Least Squares Regression Model, which was tested by use of the coefficient of determination and a t-test. The difference in regression lines of horizontal landslide length $(L h)$ and landslide height $(H)$ with basalt benches present/absent in the runout path was tested using a t-test.

\section{Results}

\subsection{Landslide database characteristics}

Examining the 67 landslides throughout the Faroe Islands revealed the following characteristics. Mean surface of rupture length and width were $36.7 \mathrm{~m}$ and $18.4 \mathrm{~m}$, respectively (Table 1). Surface of rupture depth varied from $0.2 \mathrm{~m}$ to $5.0 \mathrm{~m}$, partly reflecting the variation in soil depth in the Faroe Islands, since $60 \%$ of the landslides had slide planes occurring entirely or partly along the contact zone between soil and underlying rock (Table 1). Surface of rupture lengths, widths, depths and landslide volumes all had high CVs (Table 1), reflecting the large variation of the size and shape of the investigated landslides.

Slope angles for landslide initiation varied from $22^{\circ}$ to $40^{\circ}$, with a mean value of $32^{\circ}$ and a CV of 0.12 . From calculated landslide ratios, which varied from 0.5 to 7.9 on landslide prone slope angles (Table 2), it was decided to set the lower and higher slope angle thresholds for landslide initi-

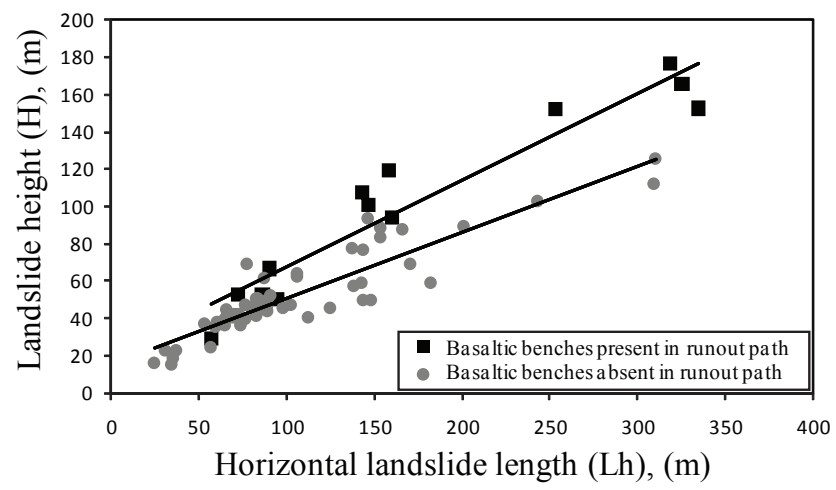

Fig. 4. Correlations between landslide height $(H)$ and horizontal landslide length $(L h)$ with basalt benches either present or absent in runout path.

ation in the susceptibility map at $25^{\circ}$ and $40^{\circ}$, respectively. Slope angles between $20^{\circ}$ and $25^{\circ}$ were excluded because of the very low landslide ratio of 0.5 . Moreover, Table 2 shows that no landslides occur on slopes $<20^{\circ}$ and $>40^{\circ}$. Slopes which are gentler are considered too flat to provide landsliding, while the absence of landslides on very steep slopes is caused by the fact that soil has already slid away in this steep landscape. Furthermore upper slope angles on straight slopes are not much steeper than $40^{\circ}$; limited by the angle of repose.

\subsection{Runout characteristics}

AOR values varied from $9.0^{\circ}$ to $42.0^{\circ}$. The highly significant $\left(r^{2}=0.827, p<0.01\right)$ regression line: $H=0.43 L h+10.80$ (Table 3), was used for calculating an overall average AOR of $24.8^{\circ}$.

A strong relationship was found between AOR and landscape topography. Regression lines when basalt benches 
Table 1. Selected landslide characteristics, obtained from the landslide database.

\begin{tabular}{lccc}
\hline Landslide parameter & Value range & Mean & Coefficient of variation (CV) \\
\hline Surface of rupture length $(\mathrm{m})$ & $10.3-100.3$ & 36.7 & 0.54 \\
Surface of rupture width $(\mathrm{m})$ & $5.9-62.4$ & 18.4 & 0.47 \\
Surface of rupture depth $(\mathrm{m})$ & $0.2-5.0$ & 1.4 & 0.64 \\
Landslide volume $\left(\mathrm{m}^{3}\right)$ & $15.9-14216.4$ & 772.3 & 2.31 \\
\hline Slide plane type & & Number of slide planes \\
Soil & & 27 \\
Rock contact & & 17 \\
Soil and rock contact & & 23 \\
\hline
\end{tabular}

Table 2. Distribution of landslides from the landslide database at different slope angles in the Faroese Islands.

\begin{tabular}{ccccc}
\hline Slope angle & $\begin{array}{c}\text { Number of } \\
\text { landslides }\end{array}$ & $\begin{array}{c}\% \text { of } \\
\text { landslides }\end{array}$ & $\begin{array}{c}\text { \% of the total } \\
\text { Faroese landscape }\end{array}$ & $\begin{array}{c}\text { Landslide } \\
\text { ratio }^{\mathrm{a}}\end{array}$ \\
\hline$<20^{\circ}$ & 0 & 0 & 53.4 & 0 \\
$20-25^{\circ}$ & 3 & 4.5 & 9.4 & 0.5 \\
$25-30^{\circ}$ & 8 & 11.9 & 8.3 & 1.4 \\
$30-35^{\circ}$ & 27 & 40.3 & 7.6 & 5.3 \\
$35-40^{\circ}$ & 29 & 43.3 & 5.5 & 7.9 \\
$>40^{\circ}$ & 0 & 0 & 15.8 & 0 \\
\hline
\end{tabular}

a: $\%$ of landslides $/ \%$ of the total Faroese landscape

were present vs. absent in the runout path (Fig. 4) were significantly different $(p<0.05)$, (Table 3$)$. The two highly significant regression lines $\left(r^{2}=0.909, p<0.01\right)$ and $\left(r^{2}=0.816\right.$, $p<0.01$ ), (Table 3 ) were used for calculating AOR when basalt benches were present vs. absent in the runout path. The two AOR values, $27.6^{\circ}$ and $21.5^{\circ}$, were calculated using Eq. (2) in order to delineate runout zones in the study area. No significant correlation was found between AOR and landslide volume (Table 3).

\subsection{Landslide susceptibility map}

The landslide susceptibility map of the study area is shown in Fig. 5. The map holds information about both landslide initiation areas and runout zones which made up $1.63 \mathrm{~km}^{2}$ $(20 \%)$ and $3.91 \mathrm{~km}^{2}(48 \%)$ of the study area, respectively.

Landslide susceptible areas were seen to potentially affect existing buildings and infrastructure in the outskirts of the town. Non-susceptible areas were typically seen inside Klaksvík, in cirque valleys and on essentially flat mountain plateaus.

\subsection{Validation}

To evaluate the prediction skill of the susceptibility model, the spatial occurrence of 87 actual landslides in the study

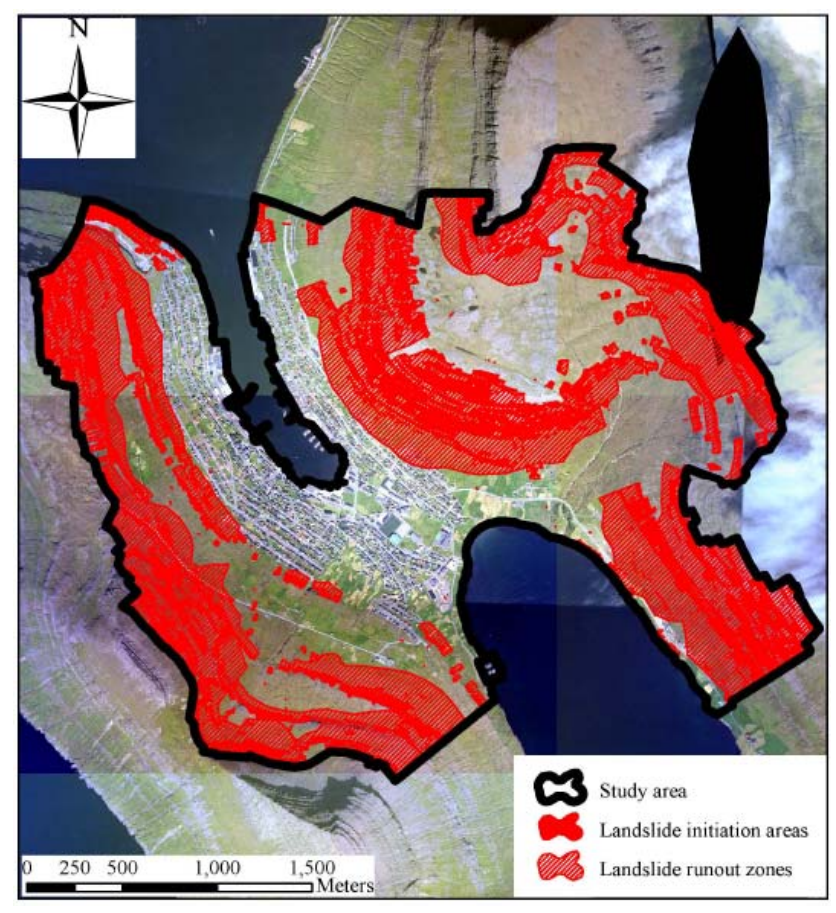

Fig. 5. Landslide susceptibility map of the study area at Klaksvík.

area used as a validation set, were subdivided into initiation areas and runout zones. Of the total $2.1 \times 10^{-2} \mathrm{~km}^{2}$ actual landslide initiation areas, $69 \%$ were within the predicted initiation areas (Table 4), 20\% were located in predicted runout zones, while $11 \%$ were found in areas predicted as non susceptible to landsliding (Table 4).

When comparing predicted and actual landslide runout zones, predicted landslide initiation areas were also predicted as being runout zones. This assumption was made since runout material was observed to be naturally represented in initiation areas as a consequence of deposition which began immediately downslope from landslide scars. $92 \%$ of the actual $5.7 \times 10^{-2} \mathrm{~km}^{2}$ landslide runout zone areas were found in predicted runout zones, while $8 \%$ were present in areas 
Table 3. Statistical analysis of runout characteristics.

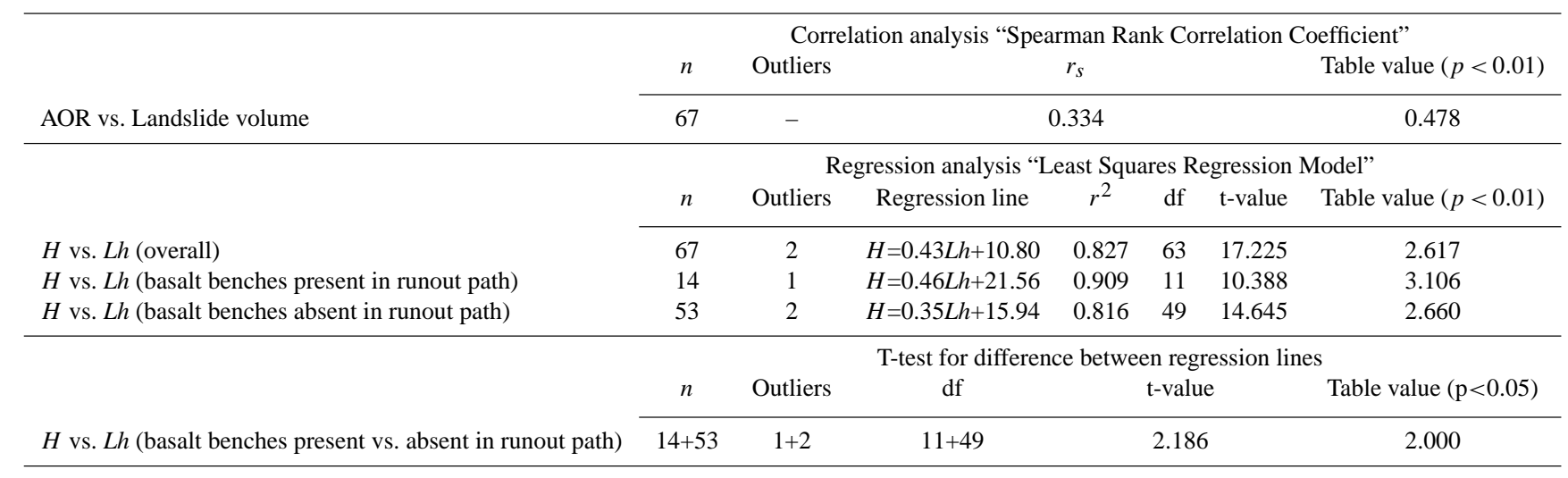

Table 4. Validation of the landslide susceptibility map by comparing actual and predicted landslide initiation areas and runout zones.

\begin{tabular}{lccc}
\hline & $\begin{array}{c}\text { Predicted initiation } \\
\text { areas }\end{array}$ & $\begin{array}{c}\text { Predicted runout } \\
\text { zones }\end{array}$ & $\begin{array}{c}\text { Predicted non } \\
\text { susceptible areas }\end{array}$ \\
\hline Actual initiation areas & $69 \%$ & $20 \%$ & $11 \%$ \\
Actual runout zones & - & $92 \%$ & $8 \%$ \\
\hline
\end{tabular}

predicted as non susceptible to landsliding (Table 4). Furthermore, 76 of the 87 actual landslides were found in the overall predicted landslide susceptibility areas, corresponding to an accuracy of $87 \%$.

\section{Discussions and conclusions}

In this study slope angles for landslide initiation varied from $22^{\circ}$ to $40^{\circ}$, which is consistent with results from Dahl (2007), where the lower threshold for landslide initiation was estimated to be $25^{\circ}$. Other studies on landslides which are also shallow, translational and within a temperate climate regime have also shown consistency with respect to slope angle values. D'Amato Avanzi et al. (2004) recorded slope angles for landslide initiation between $25^{\circ}$ and $>45^{\circ}$ with metamorphic sandstone and phyllite as parent material. Slope angles up to $45^{\circ}$ was reported by Shakoor and Smithmyer (2005), with mudrock as parent material, while Matsushi et al. (2006) found slope angles between $32^{\circ}$ and $38^{\circ}$ with mudstone and sandstone as parent material.

In this study calculated AOR values differed significantly with the presence/absence of basalt benches in the runout path. Although no earlier studies have examined the influence of geological benches on AOR, obstructions in the runout path have generally been proven to increase AOR. Corominas (1996), plotting log landslide volume for rockfalls, earthflows and translational landslides against log landslide height $(H)$ /horizontal landslide length $(L h)$, showed that notably rockfalls and debris flows with volumes $<1 \times 10^{4} \mathrm{~m}^{3}$ developed higher AOR when obstructing elements were present in the runout path compared to unobstructed runout paths. Obstructing elements were dense forest, scree deposits, opposing valley slopes and deflections of the runout material. Higher AOR values in obstructed runout paths were also found in Corominas et al. (2003). Differences in AOR, when investigating rock falls, shallow translational and rotational slides, were in the range of 2 $10^{\circ}$ between obstructed and unobstructed runout paths, with AOR values varying from $20^{\circ}$ to $54^{\circ}$. Obstructing elements were dense forest, large blocks and opposing valley slopes (Corominas et al., 2003). Hence, when comparing the runout results in this paper with the ones reported from Corominas (1996) and Corominas et al. (2003) it is recognized that basalt benches in the runout path can be regarded as obstructions which significantly increase AOR values. The increase in AOR with the presence of basalt benches can be explained by conceptually evaluating the AOR approach and by looking at Fig. $3 \mathrm{~b}$. Since the AOR is the angle connecting the crown of a landslide scar with the distal margin of the runout material, and $\tan (\mathrm{AOR})$ therefore represents the dynamic friction coefficient, the runout material will decelerate, as it approaches the AOR point in the runout path. To be exact, deceleration will occur when the slope angle becomes smaller than the AOR. If the runout material overruns several basalt benches in its path, as is seen in Fig. 3b, it approaches the AOR point several times, each 
time decelerating. Eventually the repetitive decelerations causes the runout material to stop causing a higher AOR than on purely concave slopes, where runout material is not exposed to the same repetitive decelerations. Thus $\tan (\mathrm{AOR})$ on purely concave slopes can be seen as representing the "true" dynamic friction coefficient of the runout material. This also explains why the runout material can cross the AOR point several times when overrunning basalt benches in the runout path, since $\tan (\mathrm{AOR})$ in the presence of basalt benches does not represent the true dynamic friction coefficient of the runout material. The latter theoretical consideration has been verified by inserting AOR-lines representing the true dynamic friction coefficient (from $\mathrm{AOR}=21.5^{\circ}$ ) into all landscape profiles containing basalt benches in the runout path (Fig. 3b). When doing so, topographic profiles were no longer intersected by the AOR-lines.

A large number of studies have investigated the potential negative correlation between landslide volume and AOR. Corominas et al. (2003) found a decrease in AOR of $7^{\circ}$ with increase in landslide volume from $1 \mathrm{~m}^{3}$ to $2 \times 10^{3} \mathrm{~m}^{3}$. The same tendency was seen in Corominas (1996) in a logarithmic correlation between $\tan (\mathrm{AOR})$ and landslide volumes up to $1 \times 10^{10} \mathrm{~m}^{3}$, and in Dai and Lee (2002), which used landslide width as an indirect measure of landslide volume. Translational landslides with a width of $<20 \mathrm{~m}$ and $>20 \mathrm{~m}$ had AOR of $29.0^{\circ}$ and $26.7^{\circ}$, respectively (Dai and Lee, 2002). However, Scheidegger (1973) and Hsü (1975), comparing landslide volumes with $\tan ($ AOR) for a large variety of landslides, indicated that this negative correlation only exists for landslides above $1 \times 10^{5} \mathrm{~m}^{3}$ to $0.5 \times 10^{6} \mathrm{~m}^{3}$. This argument was supported by Okura et al. (2003), who found no significant correlation between landslide volume and $\tan (\mathrm{AOR})$ for translational landslides between $1 \times 10^{2}$ to $1.5 \times 10^{3} \mathrm{~m}^{3}$. Thus the non significant correlation between AOR and landslide volume in this paper is believed to be caused by the relatively small landslide volumes $<1.5 \times 10^{4} \mathrm{~m}^{3}$ (Table 1 ).

In this paper $69 \%$ of actual landslide initiation areas were correctly located in the predicted susceptibility areas (Table 4), while $20 \%$ were found in predicted runout zones and the remaining $11 \%$ were found in areas predicted as nonsusceptible. Potential causes for the model inaccuracy are considered later in this discussion. The $69 \%$ correctly predicted landslide initiation areas show a good correspondence with another qualitative study, where Ruff and Czurda (2008) found $67 \%$ of actual landslide areas to be correctly predicted in high and very high susceptibility areas, using an expert evaluation approach. Compared to these qualitative studies Ayalew et al. (2005) and Duman et al. (2006) found 63\% and $80 \%$ of actual landslide areas to be correctly predicted in high and very high susceptibility areas using statistical approaches. Moreover, in this paper $87 \%$ of actual landslides were found in the overall predicted landslide susceptibility areas, which is consistent with results from other qualitative and quantitative studies. In a qualitative study Sarkar and Anbalagan (2008) found 63\% of actual landslides in predicted high and very high susceptibility areas, using an expert evaluation approach. Dai and Lee (2002) and DomínguezCuesta et al. (2007) found $85 \%$ and $92 \%$ of actual landslides in predicted high, very high and extremely high susceptibility areas using statistical approaches, and finally AlcantaraAyala (2004) found $81 \%$ of actual landslides in predicted susceptibility zones using a mechanistic approach. Directly comparing the results from this paper with these other studies is however somehow problematic. The studies used for comparison have worked with a whole range of susceptibility levels, instead of simply defining an area as being susceptible or non-susceptible, as is the case in this paper. Nevertheless the comparison gives an indication that the simple approach with only a few key parameters tested in this paper performs equally well as several other qualitative and quantitative landslide susceptibility models applied.

In this paper $92 \%$ of actual landslide runout zones were correctly located in the predicted runout zones. Verification data for runout zones comparable to results in this paper is hardly present in the literature. However, as pointed out by Wong and Ho (1996) the AOR approach has proven to give a very realistic assessment of landslide runout distance, as well as calculated runout distances using the AOR approach having proved very consistent with results from numerical approaches (Corominas et al., 2003).

An argument when evaluating the applicability of a landslide susceptibility approach is its ability to be extrapolated to other or larger geographical areas. Identification of landslide initiation areas in other and larger parts of the Faroe Islands can easily be done, since the DEM and digital orthophotos are available for the entire archipelago. A greater challenge lies within identifying landslide runout zones for larger areas. In this paper, a total number of 725 downslope endpoints for runout were manually delineated in the study area. In order to determine landslide runout zones at an acceptable time and cost, large parts of the analysis has to be automated within a GIS. While landscape profiles can still be drawn manually because they are not time consuming and are used to define the initiation points and direction of the runout path, downslope endpoints and hence runout lengths should be automatically generated by the use of ESRI ArcGIS tools.

The susceptibility model in this paper showed some inaccuracy, since $20 \%$ of actual landslide initiation areas were incorrectly found in predicted runout zones, as well as $11 \%$ of actual landslide initiation areas and $8 \%$ of observed runout zones were found in areas predicted as non-susceptible. Even though the $20 \%$ of actual landslide initiation areas found in predicted runout zones may rarely be a problem in a planning perspective, since delineated runout zones are a part of the landslide susceptibility areas, it is still important to evaluate potential causes for the model inaccuracy. Imprecision may be caused by the following five factors: 1) Limitations of the DEM. The resolution of the DEM is limited by the properties of the topographical map from which it has 
been constructed (cf. Sect. 4.2). Thus local changes in slope angle, which are important for determining landslide initiation areas and runout zones as well as for assessing landslide heights and runout lengths, may not be correctly shown by the DEM. 2) Defined slope angle thresholds for landslide initiation areas. Subsequent slope angle measurements in GIS of actual landslide initiation areas in the study area indicated slope angles below $25^{\circ}$ or above $40^{\circ}$. Hence, the model could possibly be improved by including such slope angles when defining landslide initiation areas. 3) Inaccuracies in the calculated AOR values, caused by the difficulty in determining exact horizontal landslide lengths. As a consequence of increasing landslide age, in many cases horizontal landslide length was difficult to measure, since distal margins of the runout material were no longer recognized as sharp boundaries. 4) The presence of AOR values lower than the $21.5^{\circ}$ and $27.6^{\circ}$ used in the model. Subsequent analysis have shown that such lower AOR values may account for app. $1 \%$ of the $8 \%$ observed runout zones found in areas predicted as non-susceptible. Thus, low AOR values only represent a minor problem in the applicability of the susceptibility model. 5) Contribution of several geological, geomorphologic or soil parameters to landsliding, which were not included in this approach. Dahl (2007) indicated that root density can influence the spatial distribution of landslides in the Faroese landscape. Furthermore, from the literature it is well known, that a large number of parameters such as slope altitude, slope aspect, vegetation, land use, geology, soil depth, soil cohesion and proximity to drainage lines can affect landslide susceptibility. A demand for including more parameters in the susceptibility assessment could lead to another study with the purpose to obtain an improved accuracy of the predicted susceptibility. Including more parameters could either be done through a more comprehensive qualitative expert evaluation or through a quantitative statistical approach. The argument for not using a mechanistic approach is that large local variations in soil properties, which are found in the Faroe Islands Hansen (1990), Dahl (2007) and Veihe and Thers (2007) are problematic in such methods, which imply the ground conditions in a chosen study area to be fairly uniform (Dai and Lee, 2002; Dai et al., 2002).

Unlike what is seen in many other landslide susceptibility studies, the current approach does not divide the landscape into differentiated susceptibility classes, but simply classify the study area as being susceptible or non susceptible to landsliding. This simple zonation terminology may be insufficient in some communities where infrastructure and urban expansion is very intense and where areas moderately susceptible to landsliding therefore need to be utilized for buildings or infrastructure. However, in the Faroe Islands and other societies where human expansion problems are less intense although still important, the simple zonation terminology can be a sufficient tool for planning purposes. Furthermore, this paper sets an example of, how it is possible to effectively map landslide susceptibility using a simple ap- proach with few parameters, which requires only little work and small economic resources. Hence it could be relevant to test this approach for mapping landslide susceptibility in parts of the World, where funds for scientific research is limited. Finally the approach for mapping landslide runout zones, where AOR is dependent on the presence/absence of basalt benches in the runout path could be adopted when mapping landslide susceptibility in similar landscapes, where basalt benches are dominant.

Acknowledgements. This paper has been carried out in cooperation between Department of Environmental, Social and Spatial Change, Roskilde University, Denmark and Jarðfeingi (Faroese Earth and Energy Directorate), the Faroe Islands. The authors wish to thank Dr Esbern Holmes for technical GIS assistance and Ritta Bitsch for graphical preparations.

Edited by: T. Glade

Reviewed by: J. Corominas and another anonymous referee

\section{References}

Alcantara-Ayala, I.: Hazard assessment of rainfall-induced landsliding in Mexico, Geomorphology, 61, 19-40, 2004.

Ayalew, L. and Yamagishi, H.: The application of GIS-based logistic regression for landslide susceptibility mapping in the KakudaYahiko Mountains, Central Japan, Geomorphology, 65, 15-31, 2005.

Ayalew, L., Yamagishi, H., Marui, H., and Kanno, T.: Landslides in Sado Island of Japan: Part II. GIS-based susceptibility mapping with comparisons of results from two methods and verifications, Eng. Geol., 81, 432-445, 2005.

Brabb, E. E.: Innovative approaches to landslide hazard and risk mapping, in: Proceedings of the 4th International Symposium on Landslides, Toronto, Canada, 16-21 September 1984, 307-324, 1984.

Cannon, S. H. and Savage, W. Z.: A mass change model for debris flow, J. Geol., 96, 221-227, 1988.

Cappelen, J. and Laursen, E. V.: The Climate of the Faroe Islands with Climatological Standard Normals, 1961-1990, Danish Meteorological Institute, Ministry of Transport, Denmark, Technical report 98-14, 1998.

Christiansen, H. H.: Highland Aeolian Deposits in the Faroe Islands, Fróðskaparrit, 46, 205-213, 1998.

Christiansen, H. H., Blikra, L. H., and Mortensen, L. E.: Holocene slope processes and landforms in the northern Faroe Islands, Earth Env. Sci. T. R. So., 98, 1-13, 2007.

Christiansen, H. H. and Mortensen, L. E.: Arctic Mountain Meteorology at the Sornfelli Mountain in Year 2000 in the Faroe Islands, Fróðskaparrit, 50, 93-110, 2002.

Collins, B. D. and Znidarcic, D.: Stability Analysis of Rainfall Induced Landslides, J. Geotech. Geoenviron., 130, 362-372, 2004.

Corominas, J.: The angle of reach as a mobility index for small and large landslides, Can. Geotech. J., 33, 260-271, 1996.

Corominas, J., Copons, R., Vilaplana, J. M., Altimir, J., and Amigó, J.: Integrated Landslide Susceptibility Analysis and Hazard Assessment in the Principality of Andorra, Nat. Hazards, 30, 421435, 2003. 
Cruden, D. M. and Varnes, D. J.: Landslide Types and Processes, in: Landslides investigation and mitigation, edited by: Turner, A. K. and Shuster, R. L., Transportation Research Board, Special Report 247, National Academy Press, Washington D.C., USA, 36-75, 1996.

Dahl, M.-P. J.: Landslides in the Faroe Islands - An Analysis of Triggering Parameters, M.Sc. Thesis, Roskilde University, Denmark, 2007 (in Danish with English Abstr.).

Dai, F. C. and Lee, C. F.: Landslide characteristics and slope instability modeling using GIS, Lantau Island, Hong Kong, Geomorphology, 42, 213-228, 2002.

Dai, F. C., Lee, C. F., and Ngai, Y. Y.: Landslide risk assessment and management: an overview, Eng. Geol., 64, 65-87, 2002.

D'Amato Avanzi, G., Giannecchini, R., and Puccinelli, A.: The influence of the geological and geomorphological settings on shallow landslides. An example in a temperate climate environment: the June 19, 1996 event in northwestern Tuscany (Italy), Eng. Geol., 73, 215-228, 2004.

De Blasio, F. V., Elverhøi, A., Issler, D., Harbitz, C. B., Bryn, P., and Lien, R.: On the dynamics of subaqueous clay rich gravity mass flows - the giant Storegga slide, Norway, Mar. Petrol. Geol., 22, 179-186, 2005.

Domínguez-Cuesta, M. J., Jiménez-Sánchez, M., and Berrezueta, E.: Landslides in the Central Coalfield (Cantabrian Mountains, NW Spain): Geomorphological features, conditioning factors and methodological implications in susceptibility assessment, Geomorphology, 89, 358-369, 2007.

Duman, T. Y., Can, T., Gokceoglu, C., Nefeslioglu, H. A., and Sonmez, H.: Application of logistic regression for landslide susceptibility zoning of Cekmece Area, Istanbul, Turkey, Environ. Geol., 51, 241-256, 2006.

Guinau, M., Vilajosana, I., and Vilaplana, J. M.: GIS-based debris flow source and runout susceptibility assessment from DEM data - a case study in NW Nicaragua, Nat. Hazards Earth Syst. Sci., 7, 703-716, 2007, http://www.nat-hazards-earth-syst-sci.net/7/703/2007/.

Hansen, L. E.: Soil Development in the Leynavatn Area, M.Sc. Thesis, University of Copenhagen, Denmark, 1990 (in Danish).

He, Y. and Beighley, E.: GIS-based regional landslide susceptibility mapping: a case study in southern California. Earth Surf. Proc. Land., 33, 380-393, 2008.

Heim, A. (Ed.): Bergsturz and Menschenleben, Fretz \& Wasmuth Verlag A.G., Zürich, 1932.

Hsü, K. J.: Catastrophic Debris Streams (Sturzstroms) Generated by Rockfalls, Geol. Soc. Am. Bull., 86, 129-140, 1975.

Huabin, W., Gangjun, L., Weiya, X., and Gonghui, W.: GIS-based landslide hazard assessment: an overview, Prog. Phys. Geog., 29, 548-567, 2005.

Humlum, O.: Main Shapes of the Landscape Funningur, Slættaratindur, in: Topographic Atlas the Faroe Islands, edited by: Guttesen, R., Royal Danish Geographical Society, Copenhagen, Denmark, 38-41, 1996 (in Danish).

Humlum, O.: Rock glaciers on the Faeroe Islands, the North Atlantic, J. Quaternary Sci., 13(4), 293-307, 1998.

Hutchinson, J. N.: A sliding-consolidation model for flow slides, Can. Geotech. J., 23, 115-126, 1986.

Hürlimann, M., Copons, R., and Altimir, J.: Detailed debris flow hazard assessment in Andorra: A multidisciplinary approach, Geomorphology, 78, 359-372, 2006.
Ives, J. D. and Messerli, B.: Mountain hazards mapping in Nepal - Introduction to an applied mountain research project, Mt. Res. Dev., 1, 223-230, 1981.

Jørgensen, G.: Landslides and related phenomena on Suðuroy, the Faroe Islands, Bull. Geol. Soc. Den., 27, Special Issue, 85-89, 1978.

Lawson, I. T., Church, M. J., McGovern, T. H., Arge, S. V., Woolet, J., Edwards, K. J., Gathorne-Hardy, F. J., Dugmore, A. J., Cook, G., Mairs, K.-A., Thomson, A. M., and Sveinbjarnardóttir, G.: Historical Ecology on Sandoy, Faroe Islands: Palaeoenvironmental and Archaeological Perspectives, Hum. Ecol., 33, 651-684, 2005.

Magliulo, P., Di Lisio, A., Russo, F., and Zelano, A.: Geomorphology and landslide susceptibility assessment using GIS and bivariate statistics: a case study in southern Italy, Nat. Hazards, 47, 411-435, 2008.

Malgot, J. and Mahr, T.: Engineering geological mapping of the west Carpathian landslide areas, Bulletin of the International Association of Engineering Geology, 19, 116-121, 1979.

Matsushi, Y., Hattanji, T., and Matsukura, Y.: Mechanisms of shallow landslides on soil-mantled hillslopes with permeable and impermeable bedrocks in the Boso Peninsula, Japan, Geomorphology, 76, 92-108, 2006.

McDougall, S. and Hungr, O.: A model for the analysis of rapid landslide motion across three-dimensional terrain, Can. Geotech. J., 41, 1084-1097, 2004.

Mortensen, L. E.: Landslides and weather conditions, Frøði, 1, 1822, (in Faroese), 2001.

Mortensen, L. E.: The risk of landslides may be increasing, Sosialurin, 1/5, 2004 (in Faroese).

Morton, D. M., Alvarez, R. M., and Campbell, R. H.: Preliminary soil-slip susceptibility maps, southwestern California, US Geological Survey, USA, Open File Rep. 03-17, 2003.

Okura, Y., Kitahara, H., Kawanami, A., and Kurokawa, U.: Topography and volume effects on travel distance of surface failure, Eng. Geol., 67, 243-254, 2003.

Passey, S. R. and Bell, B. R.: Morphologies and emplacement mechanisms of the lava flows of the Faroe Islands Basalt Group, Faroe Islands, NE Atlantic Ocean, B. Volcanol., 70, 139-156, 2007.

Rasmussen, J. and Noe-Nygaard, A.: Description to Geological Map of the Faroe Islands, 1st series, 24, Geological Survey of Denmark, Copenhagen, Denmark, 1969a (in Danish).

Rasmussen, J. and Noe-Nygaard, A.: Geological Map of the Faroe Islands, 1st series, 24, Geological Survey of Denmark, Copenhagen, Denmark, 1969b (in Danish).

Ruff, M. and Czurda, K.: Landslide susceptibility analysis with a heuristic approach in the Eastern Alps (Vorarlberg, Austria), Geomorphology, 94, 314-324, 2008.

Rupke, J., Cammeraat, E., Seijmonsbergen, A. C., and Van Westen, C. J.: Engineering geomorphology of the Widentobel catchment, Appenzell and Sankt Gallen, Switzerland. A geomorphological inventory system applied to geotechnical appraisal of slope stability, Eng. Geol., 26, 33-68, 1988.

Rutherford, G. K. and Debenham, P. L.: The mineralogy of some silt and clay fractions from soils on the Faeroe Islands, Soil Sci. 132, 288-299, 1981.

Sarkar, S. and Anbalagan, R.: Landslide Hazard Zonation Mapping and Comparative Analysis of Hazard Zonation Maps, J. Mt. Sci., 
5, 232-240, 2008.

Sassa, K.: Special lecture: Geotechnical model for the motion of landslides, in: Proceedings of the 5th International Symposium on Landslides, Lausanne, Switzerland, 10-15 July 1988, 37-55, 1988.

Scheidegger, A. E.: On the Prediction of the Reach and Velocity of Catastrophic Landslides, Rock Mech., 5, 231-236, 1973.

Selby, M. J. (Ed.): Hillslope Materials and Processes, 2nd ed., Oxford University Press, Oxford, UK, 1993.

Shakoor, A. and Smithmyer, A. J.: An analysis of storm-induced landslides in colluvial soils overlying mudrock sequences, southeastern Ohio, USA, Eng. Geol., 78, 257-274, 2005.

Soeters, R. and Van Westen, C. J.: Slope instability recognition, analysis, and zonation, in: Landslides investigation and mitigation, edited by: Turner, A. K. and Shuster, R. L., Transportation Research Board, Special Report 247, National Academy Press, Washington D.C., USA, 129-177, 1996.

Terlien, M. T. J., Van Westen, C. J., and Van Asch, T. W. J.: Deterministic modeling in GIS-based landslide hazard assessment, in: Geographical Information Systems in Assessing Natural Hazards, edited by: Carrara, A. and Guzzetti, F., Kluwer Academic Publishers, Dordrecht, The Netherlands, 57-77, 1995.
USDA.: Soil Taxonomy, A Basic System of Soil Classification for Making and Interpreting Soil Surveys, Agriculture Handbook No. 436, Washington D.C., USA, 1975.

Valentino, R., Barla, G., and Montrasio, L.: Experimental Analysis and Micromechanical Modelling of Dry Granular Flow and Impacts in Laboratory Flume Tests, Rock Mech. Rock Eng., 41, 153-177, 2008.

Veihe, A. and Thers, M.: Pedogenesis and root development in a complex geomorphologic setting in the Faroe Islands, Commun. Soil Sci. Plan., 38, 293-314, 2007.

Wachal, D. J. and Hudak, P. F.: Mapping landslide susceptibility in Travis County, Texas, USA, GeoJournal, 51, 245-253, 2000.

Wang, C., Li, S., and Esaki, T.: GIS-based two-dimensional numerical simulation of rainfall-induced debris flow, Nat. Hazards Earth Syst. Sci., 8, 47-58, 2008, http://www.nat-hazards-earth-syst-sci.net/8/47/2008/.

Ward, T. J.: Factor of Safety approach to landslide potential delineation, In partial fulfillment of the requirements for the Degree of Doctor of Philosophy, Colorado State University, Fort Collins, Colorado, USA, 1976.

Wong, H. N. and Ho, K. K. S.: Travel distances of landslide debris, in: Proceedings of the 7th International Symposium on Landslides, Trondheim, Norway, 17-21 June 1996, 417-422, 1996.

Wu, W. and Sidle, R. C.: A distributed slope stability model for steep forested basins, Water Resour. Res., 31, 2097-2110, 1995. 